\title{
Marketing de Experiência: um estudo dos aspectos conceituais
}

\author{
MARIA TERESA GRIMALDI LAROCCA ${ }^{1}$ \\ RODRIGO LADEIRA ${ }^{1}$ \\ ÁURIO LÚCIO LEOCÁDIO DA SILVA ${ }^{2}$ \\ Ricardo Coutinho MELLO ${ }^{1}$ \\ ${ }^{1}$ Universidade Federal da Bahia (UFBA) / Departamento de AdMINISTRAÇÃo, SALVAdor - BA, Brasil \\ 2 UniversidAde Federal do CEARÁ (UFC) / Departamento de AdMINISTRAÇÃO, ForTALEZA - CE, BRAsIL
}

\section{Resumo}

O presente estudo teve como objetivo central revisar a evolução e atuais conceitos de marketing de experiência segundo os principais autores que se dedicaram ao entendimento desse campo. O tema faz parte das prioridades de pesquisa do Marketing Science Institute Research Priorities, que aponta as prevalências de estudos para a área de marketing. Embora o tema esteja presente na literatura nacional e internacional, os estudos conceituais são encontrados em menor número. Dada a sua importância, esse estudo propõe um entendimento de marketing de experiência, examinado sob uma abordagem conceitual, baseado na apreciação crítica de conceitos relacionados ao marketing de experiência com as dimensões propostas por Schmitt (1999, 2002, 2006, 2010) e na tipologia proposta por Lanier Junior e Rader (2015), considerando que o nível de explicação e intencionalidade de um experimento pode variar para cada consumidor da mesma experiência. O marketing de experiência surge como a nova onda do marketing contemporâneo, proporcionando fidelização e relacionamento, foco dos dias atuais nesta área de estudos.

Palavras-chave: Marketing de experiência. Marketing experiencial. Definição de marketing de experiência.

\section{Experience marketing: a study of the conceptual aspects}

\begin{abstract}
The main objective of this study was to review the evolution and current concepts of experience marketing according to the main authors who were dedicated to the understanding of this field. The subject is part of the Marketing Science Institute Research Priorities, which points out the prevalence of studies for the marketing field. Although the subject is present in the national and international literature, there are few conceptual studies. Given the importance of the topic, this research proposes a form of understanding the phenomenon of experience marketing, exploring a conceptual approach based on the critical appreciation of concepts related to experience marketing adopting the dimensions proposed by Schmitt $(1999,2002,2006,2010)$ and the typology proposed by Lanier Junior and Rader (2015). The research considers that the level of explanatory capacity and the level of intentionality of an experiment may vary for each consumer in the same experiment. Experience marketing emerges as the new wave of contemporary marketing, and provides the most consumer loyalty and relationship, which are elements emphasized in this area of study.
\end{abstract}

Keywords: Experience marketing. Experiential marketing. Definition of experience marketing.

\section{Marketing de Experiencia: un estudio de los aspectos conceptuales}

\section{Resumen}

El presente estudio tuvo como objetivo central revisar la evolución y los conceptos actuales de marketing de experiencia según los principales autores que se dedicaron al estudio de ese campo. El tema forma parte de las prioridades de investigación del Marketing Science Institute Research Priorities, que apunta las prevalencias de estudios para el área de marketing. Aunque el tema está presente en la literatura nacional e internacional, los estudios conceptuales se encuentran en menor número. Dada su importancia, este estudio propone una comprensión del marketing de experiencia, examinada bajo un enfoque conceptual, basado en una apreciación crítica de los conceptos relacionados con el marketing de experiencia, usando las dimensiones propuestas por Schmitt (1999, 2002, 2006, 2010) y la tipología propuesta por Lanier Junior y Rader (2015), considerando que el nivel de explicación e intencionalidad de un experimento puede variar para cada consumidor de la misma experiencia. El marketing de experiencia surge como la nueva ola del marketing contemporáneo, y el que más proporciona fidelización y relación, foco de los días actuales en esta área de estudios.

Palabras clave: Marketing de experiencia. Marketing experiencial. Definición de marketing de experiencia. 


\section{INTRODUÇÃO}

O interesse em investigar o campo do marketing de experiência se deu por se tratar de um dos temas atuais de estudo na área de marketing. O Marketing Science Institute Research Priorities (MSI, 2017), que aponta as prevalências de estudos nessa área, apresenta como uma das prioridades de pesquisa de marketing o tema "como entregar experiências integradas e relevantes", asserção que o marketing de experiência se dedica, no período entre 2016-2018.

A ótica experiencial foi incorporada ao marketing na década de 1980, com o intuito de avançar no conhecimento do comportamento de compra dos consumidores, em um momento em que se começou a levar em conta o elemento emocional como dominante no processo de compra (MORAL MORAL e FERNÁNDEZ ALLES, 2012).

Assim, o marketing experiencial ou o marketing de experiência centra-se em criar experiências agradáveis não só no instante da compra, mas também no momento do consumo e do pós-consumo, recorrendo à criação de emoções, sentimentos e pensamentos buscando a interação do cliente com o bem ou o serviço. Dessa maneira, o núcleo central do marketing experiencial é a experiência no decorrer do consumo (MORAL MORAL e FERNÁNDEZ ALLES, 2012).

O conceito de marketing de experiência foi proposto por Schmitt $(1999,2002,2006,2010)$ que "[...] que acredita que há a necessidade de um enfoque que dê ênfase à experiência do cliente [...]" (ROESLER e MOLIANI, 2016, p. 4). Assim, a Administração de Marketing transita do produto ("o que" se consome) para a experiência ("como" se consome) e as empresas passam a gerenciar experiências ao invés de fornecer apenas bens e serviços (LIMA-FILHO, SILVESTRINI, SOUSA et al., 2010).

Nesse contexto, o objetivo central deste artigo é revisar o conceito de marketing de experiência segundo os principais autores que se dedicaram ao entendimento desse campo. Ao discutir a perspectiva de dois dos principais autores, buscamos apresentar uma proposta complementar para possibilitar avanços na compreensão do assunto do ponto de vista acadêmico.

A elaboração desse artigo se justifica por alguns motivos. Embora constatada a importância do marketing de experiência, ainda há muito a ser explorado no campo de conhecimento do marketing. 0 tema está presente na literatura nacional e internacional, a última tendo a predominância das investigações.

Na literatura internacional há estudos sobre o marketing de experiência na esfera das artes (PETKUS JUNIOR, 2004), no turismo (HANNAM, 2004), turismo e hospitalidade (YUAN e WU, 2008), em eventos culturais (ILA-LOPEZ e RODRIGUEZ-MOLINA, 2013) e no esporte (STENHOUSE, 2003). Há também pesquisas voltadas à lealdade e satisfação do consumidor (GARCÍA BOBADILLA, 2010 apud MORAL MORAL e FERNÁNDEZ ALLES, 2012; LEE et al., 2010; YOU-MING, 2010), e estudos com o foco de introduzir os conceitos sobre o tema (BARRIOS, 2012; HOLBROOK, 2000; MORAL MORAL e FERNÁNDEZ ALLES, 2012; PINE II e GILMORE, 1998; SCHMITT, 1999).

Com relação à literatura nacional, a maioria das pesquisas concentra-se no cenário do varejo (AZAMBUJA e BICHUETI, 2016; FARIAS, 2010; FLÔR e UMEDA, 2008; PALMEIRA, SEMPREBOM, FERRARI et al., 2009; ROESLER e MOLIANI, 2016), seguido por estudos sobre o marketing de experiência relativos as marcas (ARONNE e VASCONCELOS, 2009; CLARO e DIAS, 2014; COELHO e SANTOS, 2013; FRANCO, MOIA, SILVA et al., 2017; NEVES, BIZARRIAS, SILVA et al., 2017). Há ainda pesquisas relacionadas ao marketing de experiência e eventos (LOBUONO, GOSLING e RODAS VERA, 2016; LOBUONO, GOSLING, GONÇALVES et al., 2016), ao segmento de turismo (MONDO e COSTA, 2010; PINHEIRO e MELLO, 2015; STEFANINI, ALVES e MARQUES, 2018) e, mais recentemente, estudos que relacionam o tema a ações de patrocínios, seja voltado a esportes (YAMAMOTO, CORDOVA e MAZZEI, 2018) ou ao desenvolvimento de projetos e eventos (CERQUEIRA, LOPES e SILVA, 2019). Estudos conceituais (CABRERIZO e SANTOS, 2011; FARIAS, 2010; PINTO e LARA, 2010; SARGI e MATTOS, 2015) são encontrados em menor número.

Esta pesquisa reconhece que a natureza vasta e complexa das experiências de consumo é um ponto de partida para examinar essas experiências de consumo e encorajar investigações mais teóricas, além dos estudos empíricos (LANIER JUNIOR e RADER, 2015).

Neste sentido, o presente estudo propõe um entendimento sobre o marketing de experiência, examinado sob uma abordagem conceitual, com base na apreciação crítica dos conceitos relacionados ao marketing de experiência com as dimensões propostas por Schmitt $(1999,2002,2006,2010)$ e na tipologia proposta por Lanier Junior e Rader (2015), considerando que a explicabilidade, a intencionalidade de uma experiência pode variar em nível para cada consumidor da mesma experiência. Assim, o tema contribui para alargar o conhecimento dessa área, já que é um tema emergente, contemporâneo e relevante. 


\section{Marketing de Experiência: aspectos conceituais}

Marketing de experiência ou marketing experiencial é um conceito do campo do marketing que tem como finalidade proporcionar aos consumidores experiências através dos sentidos e das emoções (SARGI e MATTOS, 2015) e tem sido aplicado em áreas, tais como varejo, branding e marketing de eventos, e turismo.

A importância dos aspectos experienciais do consumo foi reconhecida primeiramente por Holbrook e Hirschman (1982) que contrapôs o modelo racional do processo do comportamento do consumidor com uma visão de experiência, ressaltando as variáveis emocionais - prazer, sonhos, fantasias, sentimentos e diversão - presentes no consumo e abrangendo o que denominaram de visão da experiência. A partir deste estudo, e em continuidade com esta ideia, diversos pesquisadores trabalharam com o mesmo entendimento, de que o processo de decisão de compra não é apenas influenciado por elementos racionais (AHOLA, 2005; HAVLENA e HOLBROOK, 1986 apud PALMEIRA, SEMPREBOM, FERRARI et al., 2009; LINDSTROM, 2005; PINE II e GILMORE, 1998; SHAW e IVENS, 2005; SHAW, 2007).

Similarmente, Fontenelle (2017) menciona Holbrook e Hirschman (1982) como aqueles que apresentaram o conceito de experiência de consumo [...] "em contraposição ao paradigma prevalecente no campo dos estudos do consumidor, a saber, o modelo de processamento de informações" (FONTENELLE, 2017, p. 107).

Desse momento em diante, desde que foi prognosticada a experiência, o marketing de experiência tem sido um tema que tem despertado o interesse de acadêmicos e profissionais de marketing em compreender o papel da experiência do cliente (BARRIOS, 2012; TYNAN e MCKECHNIE, 2010).

Os estudos têm origem nos anos 1980, mas é no final dos anos 1990 que os investigadores dão maior atenção por ser considerado um elemento essencial para compreensão do comportamento de compra do consumidor.

O marco teórico do conceito de marketing de experiência é o estudo de Schmitt de 1999, intitulado Experiential Marketing, que fixa a atenção na emoção produzida pelo desfrute de uma experiência, quando um indivíduo adquire um produto ou serviço ou uma combinação de ambos (MORAL MORAL e FERNÁNDEZ ALLES, 2012). Após esse estudo, as ideias de Schmitt $(2002,2003,2006,2010,2013)$ continuam válidas e presentes em outros trabalhos.

Adicionalmente, Farias (2010, p. 7) faz referência a Schmitt (1999) que definiu o marketing experiencial como o "[...] reconhecimento e aquisição de bens ou serviços de uma empresa ou marca após terem experimentado atividades e percebido estímulos". O marketing experiencial incentiva os clientes a tomarem decisões de compra mais rápidas e mais positivas (FARIAS, 2010).

Já para Palmeira, Semprebom, Ferrari et al. (2009, p. 3), a emoção cumpre papel fundamental no marketing experiencial, que "[...] concentra-se nas experiências dos clientes e este indivíduo torna-se emocionalmente envolvido com o objeto da experiência, algo que pode ser um produto ou um serviço".

Também para Roesler e Moliani (2016, p. 3) a emoção é o foco central, tendo como definição "[...] um termo utilizado para denominar um novo método de marketing, que busca atingir, por meio de experiências induzidas, o consumidor de forma mais emocional. O marketing experiencial não tem como foco a compra em si; ele foca na emoção".

Franco, Moia, Silva et al. (2017) referem-se ao argumento de Schmitt (2002) que no marketing experiencial, "o uso das experiências [...] deve fazer parte das estratégias do marketing, envolvendo principalmente fatores neurobiológicos e psicológicos". O comportamento do consumidor é entendido a partir da teoria e prática psicológicas para que as empresas possam desenvolver suas estratégias de comunicação e marketing com foco experiencial (FRANCO, MOIA, SILVA et al., 2017, p. 156).

Stefanini, Alves e Marques (2018, p. 64) tomam como base para definição os estudos desenvolvidos por Schmitt (1999) e defendem que o "marketing de experiência envolve diversos aspectos e não se limita a uma única dimensão [...]", fazendo referência às cinco dimensões já mencionadas por Schmitt (1999).

Yamamoto, Cordova and Mazzei (2018) mencionaram Schmitt (1999) e também consideram os atributos emocionais como ponto central. "A principal característica do Marketing de Experiência é proporcionar experiências onde os indivíduos são estimulados a terem algum tipo de estímulo emocional e assim, convencê-los a uma compra ou a uma boa Brand Equity do produto/empresa organizadora ou promotora de uma determinada experiência". 
Por fim, Cerqueira, Lopes e Silva (2019, p. 26) baseiam-se nas ideias de Schmitt já aludidas, que são "[...] as percepções, sentimentos e pensamentos que os consumidores têm quando encontram os produtos e as marcas e se engajam em atividades de consumo - bem como a memória de tais experiências". Eles enfatizam a lembrança que o consumidor guarda de suas experiências (CERQUEIRA, LOPES e SILVA, 2019).

O Quadro 1 apresenta os conceitos de marketing de experiência, segundo os principais autores que se dedicaram ao entendimento desse campo.

\section{Quadro 1}

\section{Definição de marketing de experiência}

\begin{tabular}{|c|c|}
\hline Autor & Conceito \\
\hline Schmitt $(1999$, p. 57) & $\begin{array}{l}\text { Concentra-se nas experiências dos clientes. As experiências ocorrem como } \\
\text { resultado de um encontro, passar por algo ou vivenciar coisas. Experiências } \\
\text { fornecem valores sensoriais, emocionais, cognitivos, comportamentais e } \\
\text { relacionais que substituem os valores funcionais. }\end{array}$ \\
\hline Schmitt $(2002,2006)$ & $\begin{array}{l}\text { É uma abordagem do marketing que tem o objetivo de criar diferentes tipos } \\
\text { de experiências para os clientes. O enfoque do marketing de experiência é a } \\
\text { experiência do consumidor, que resulta do encontro e da vivência de situações, } \\
\text { onde estímulos são criados para os sentidos, sentimentos e mente, substituindo } \\
\text { os valores funcionais. }\end{array}$ \\
\hline $\begin{array}{l}\text { Palmeira, Semprebom, } \\
\text { Ferrari et al. (2009) }\end{array}$ & $\begin{array}{l}\text { Concentra-se nas experiências dos clientes e este indivíduo torna-se } \\
\text { emocionalmente envolvido com o objeto da experiência. }\end{array}$ \\
\hline Schmitt (2010, p. 63) & $\begin{array}{l}\text { "Qualquer forma de atividade de marketing focada no cliente que cria uma } \\
\text { conexão com os clientes. Com base nesta visão ampla, as experiências podem } \\
\text { ser estimuladas nos produtos, embalagens, comunicações, interações na loja, } \\
\text { relações de vendas, eventos, e assim por diante. Podem ocorrer como resultado } \\
\text { de atividades on-line ou off-line." }\end{array}$ \\
\hline Farias $(2010$, p. 7) & $\begin{array}{l}\text { "Aquisição de bens ou serviços após o consumidor ter experimentado atividades e } \\
\text { percebido estímulos." }\end{array}$ \\
\hline Schmitt e Zarantonello (2013) & $\begin{array}{l}\text { O valor também está no sistema hedônico e experiencial, e na experiência de } \\
\text { consumo. }\end{array}$ \\
\hline Sargi e Mattos (2015) & Proporcionar aos consumidores experiências através dos sentidos e das emoções. \\
\hline Roesler e Moliani (2016) & $\begin{array}{l}\text { Um novo método de marketing, que busca atingir o consumidor de forma mais } \\
\text { emocional por meio de experiências induzidas. }\end{array}$ \\
\hline $\begin{array}{l}\text { Franco, Moia, Silva et al. } \\
(2017, \text { p. 156) }\end{array}$ & $\begin{array}{l}\text { "o uso das experiências [...] deve fazer parte das estratégias do marketing, } \\
\text { envolvendo principalmente fatores neurobiológicos e psicológicos". }\end{array}$ \\
\hline $\begin{array}{l}\text { Stefanini, Alves e Marques } \\
(2018, \text { p. 64) }\end{array}$ & $\begin{array}{l}\text { "marketing de experiência envolve diversos aspectos e não se limita a uma única } \\
\text { dimensão [...]". }\end{array}$ \\
\hline $\begin{array}{l}\text { Yamamoto, Cordova e Mazzei, } \\
(2018, \text { p.66) }\end{array}$ & $\begin{array}{l}\text { "proporcionar experiências onde os indivíduos são estimulados a terem algum } \\
\text { tipo de estímulo emocional". }\end{array}$ \\
\hline $\begin{array}{l}\text { Cerqueira, Lopes e Silva } \\
(2019, \text { p. 26) }\end{array}$ & $\begin{array}{l}\text { "as percepções, sentimentos e pensamentos que os consumidores têm quando } \\
\text { encontram os produtos e as marcas e se engajam em atividades de consumo- bem } \\
\text { como a memória de tais experiências". }\end{array}$ \\
\hline
\end{tabular}

Fonte: Elaborado pelos autores.

De acordo com Smith e Hanover (2016), os primeiros passos dados em direção ao Marketing de Experiência remontam ao marketing promocional, já que uma pesquisa (mencionada pelos mesmos) de meados da década de 80 apontou como resultado que $2 / 3$ das decisões de compra eram tomadas dentro da loja. Para esses autores, isso beneficiaria aquelas empresas que "combinassem a mensagem da marca com um incentivo que levasse o consumidor a ação de compra e a construção de uma história convincente com o esforço de criar uma emoção (SMITH e HANOVER, 2016, p. 5).

Um dos principais objetivos do marketing experiencial é criar buzz e conversas sobre um produto, já que as experiências ao vivo são consideradas um dos impulsionadores da comunicação boca-a-boca. Falar positivamente sobre um produto, serviço ou 
marca pode oferecer uma vantagem competitiva distinta, e é muito mais eficaz na conversão de predisposições desfavoráveis ou neutras em atitudes positivas quando comparadas às propagandas tradicionais. Isso porque o comunicador não é visto como vendendo o produto, e sim compartilhando as informações de forma expressiva. Além disso, o boca-a-boca é mais vívido, tornando-se mais acessível na memória e com mais peso nos julgamentos cognitivos (ARONNE e VASCONCELOS, 2009).

Segundo Smith e Hanover (2016), os profissionais de marketing começaram a perceber que as empresas direcionavam seus orçamentos de marketing para ações que conseguissem estar mais próximo dos seus consumidores com o objetivo de incrementar suas vendas. Esse momento foi o mesmo período do lançamento do livro de Pine e Gilmore (1998) defendendo que o crescimento da economia estaria no valor da experiência. As ações de marketing voltadas aos eventos da marca foram intensificadas com o intuito de criar experiências em que os consumidores as vivenciassem como memoráveis.

De acordo com Smith e Hanover (2016), as ações de marketing tais como propaganda, marketing promocional, marketing direto ou o marketing digital possuem um alcance limitado. $\mathrm{O}$ consumidor contemporâneo interage em tempo real com as marcas que são do seu interesse, busca menos opiniões dos vendedores e mais de outros consumidores através das redes sociais, buscando informações e buscando. Os autores defendem que atualmente, o marketing de experiência tornou-se "o novo marketing tradicional" (SMITH e HANOVER, 2016, p. 12).

\title{
Características Chave do Marketing de Experiência
}

Palmeira, Semprebom, Ferrari et al. (2009, p. 3) destacam quatro características fundamentais do marketing experiencial: a) está focado nas experiências dos clientes; b) procura compreender o significado da situação de consumo tratando-a como uma experiência holística; c) está ciente de que os clientes "querem ser entretidos, estimulados, emocionalmente afetados e criativamente desafiado" (SCHMITT, 1999, p. 29); d) é eclético, usando metodologias diferentes, buscando a interatividade.

Já para Schmitt (2006 apud MORAL MORAL e FERNÁNDEZ ALLES, 2012) as características-chave do marketing de experiência estão apresentadas no quadro 2:

\section{Quadro 2}

\section{Características chave do marketing de experiência}

\begin{abstract}
A particularidade principal é a experiência do cliente, que é resultado de um estímulo suscitado pela mente ou pelos sentidos, em situações que possibilitam interligar a marca ou empresa ao cliente. As experiências trazem valores cognitivos, emocionais e sensoriais substituindo os valores funcionais do produto.

Os indivíduos são considerados sujeitos racionais e emocionais, e em razão disso baseia suas decisões em elementos racionais e emocionais. Nesse sentido, o marketing experiencial considera que o indivíduo deseja receber estímulos e experiências repletas de criatividade e emotividade.

O cliente avalia as experiências de consumo vividas durante a situação de consumo, e não somente as características funcionais e os benefícios do produto. O exame da situação de consumo passa a ser considerado dentro de um contexto mais amplo, denominado de vetor sociocultural de consumo, amplificando para além da categoria do produto.
\end{abstract}

Fonte: Adaptado de Moral Moral e Fernández Alles (2012).

\section{As Cinco Dimensões do Marketing de Experiência}

Schmitt $(1999,2002,2006,2010)$ expôs os cinco tipos de experiência de consumo, apresentando-os como as cinco abordagens do marketing de experiência. De acordo com o autor, os consumidores podem vivenciar uma experiência através: a) dos sentidos (visão, audição, tato, paladar e olfato); b) dos sentimentos, através das emoções ou de um estado positivo de humor que ligam os consumidores favoravelmente às marcas; c) do pensamento, a cognição que são os recursos do intelecto envolvendo os clientes de maneira criativa; d) da ação, que visa experiências físicas, corporais ou atividades que expressam interesse por um determinado estilo de vida; e por fim, e) do relacionar, onde as experiências são criadas levando em conta o desejo do indivíduo de ser parte de um contexto social. 


\section{a) Dimensão sensorial}

O elemento sensorial envolve os cinco sentidos e afeta nossas percepções, julgamento e comportamento. Pode ser utilizado para avaliar a percepção de atributos abstratos como cor, sabor, textura, cheiro (BARRIOS, 2012). O uso desses fatores pode causar efeitos indesejados, tais como muitas cores podem distrair o cliente; uma música de fundo bem conhecida pode fazer com que o cliente compre menos itens e gaste menos na loja porque presta atenção à música. Portanto, o uso indevido desses fatores pode atrapalhar a decisão de compra do consumidor. O enfoque do marketing sensorial preenche as lacunas do marketing tradicional, demasiadamente racional (DAUCÉ e RIEUNIER, 2002).

Quando o potencial dos cinco sentidos do indivíduo é explorado, o objetivo é alvejar o subconsciente do consumidor. As emoções geram a lembrança daquela sensação e isto vai além de simplesmente palavras ou imagens, pois lida com as respostas imediatas dos órgãos sensoriais, intimamente ligados ao cérebro. Dessa maneira, um pensamento é criado, originando um julgamento. Esta abordagem sensorial está vinculada às zonas de percepção do indivíduo que produzem um estímulo, não necessariamente uma decisão. Todavia, um estímulo permite que o consumidor tome uma decisão (BATEY, 2010).

Dada a relevância dos cinco sentidos, cada um será examinado a seguir:

- Visão

No marketing, o olhar é um dos sentidos mais utilizado e mais estimulado. A seleção das cores, concepção do produto, o visual das campanhas, das embalagens dos produtos ou do ponto de venda são fatores de êxito ou fracasso para as empresas, já que através desse sentido os consumidores podem memorizar as marcas mais facilmente. Além das cores, o formato e o tamanho também são explorados por serem rapidamente percebidos e, em alguns casos, influenciando diretamente nossas emoções. O uso do texto também é outro elemento visual importante que merece ser destacado, pois, por intermédio desse o consumidor, pode sentir-se atraído ou não pelo produto (BARRIOS, 2012). E no que se refere ao ambiente, a luz também é um componente essencial, atuando na nossa percepção de acordo com sua intensidade (se é forte ou fraca, gera respostas comportamentais distintas dos compradores), se a fonte é natural ou artificial, aumentando ou não a sensação de bem-estar ou o tempo gasto no ambiente. Também permite orientar a busca de informações e influencia a quantidade de produtos comprados, ou seja, os clientes compram mais quando gostam da luz do ambiente (DAUCÉ e RIEUNIER, 2002).

- $\quad$ Audição

A grande maioria das comunicações de marketing é de natureza auditiva. Ouvimos com frequência mensagens no rádio, na TV, seus jingles e canções, músicas no ponto de vendas, em restaurantes e até em avião. O som da palavra induz a percepção do objeto que ela representa, aumentando as associações que uma marca pode ter (KRISHNA, 2012). As investigações destacam o impacto da música no comportamento do consumidor no varejo. Atualmente, está presente na maioria dos pontos de venda como parte integrante da atmosfera das lojas, em forma de videoclipes, TV ou música ambiente. Mesmo no caso dos food trucks, muitos eventos oferecem bandas locais ou DJs, reunindo gastronomia e música. A música tem o poder de contextualizar os diferentes produtos (GUMPERZ, 1977; DENORA, 1986 apud BARRIOS, 2012), colocando os clientes em um estado condizente com os produtos que a empresa vende. Por exemplo, tocar uma música de rock numa loja que vende guitarra. Portanto, é uma maneira de conectar o produto, atuando no comportamento de compra do cliente (BARRIOS, 2012).

- Olfato

A percepção do cheiro difere de pessoa para pessoa e as empresas devem levar isso em conta. As mulheres são mais sensíveis aos cheiros do que os homens e cada gênero tem reações distintas com relação ao odor (HIRSCH e GAY, 1991 apud BARRIOS, 2012). Estudos demonstram que as pessoas podem reconhecer cheiros com níveis mínimos de memória, mesmo após meses ou anos da sua exposição. O aroma do ambiente aumenta a lembrança e o reconhecimento das marcas (MORRIN e RATNESHWAR, 2003 apud BARRIOS, 2012), e um cheiro agradável tende a intervir positivamente na avaliação do cliente no tempo que passa na loja.

Além disso, a memória olfativa é responsável por evocar lembranças agradáveis ou desagradáveis, que interferem diretamente no processo de compra e na lealdade às marcas.

O perfume pode levar a uma experiência subjetiva aprimorada para os compradores do varejo, influenciando o tempo que os consumidores gastam na digitalização de mercadorias, na fila de espera ou na espera de ajuda. Esse tempo de espera pode parecer mais curto do que realmente é ao introduzir o perfume no ambiente. (SPANGENBERG, CROWLEY e HENDERSON, 1996). 


\section{- Degustativo (Paladar)}

Os seres humanos são capazes de distinguir cinco sabores: doce, salgado, amargo, azedo e umami (palavra de origem japonesa que significa "sabor delicioso") e são combinados com nossos outros sentidos: cheiro (aroma do alimento), toque (temperatura, textura dos alimentos), visão (como é visto incluindo a cor do alimento), ouvir (o som de um caramelo quando o mordemos). Muitos fatores atuam a percepção do gosto tais como os ingredientes utilizados ou mesmo a informação nutricional dos produtos (BARRIOS, 2012). O paladar é o sentido abordado por produtos do setor alimentício. Está quimicamente ligado ao olfato, um completando o outro. O olfato desperta o paladar, que sem o cheiro praticamente não funciona. Pessoas idosas têm este sentido menos apurado, pois com o envelhecimento os receptores degustativos ficam falhos. Já as crianças têm este sentido muito forte (OLIVEIRA e BRAGA, 2013). Portanto, podemos encontrar diferentes emoções conforme a faixa etária para esse sentido.

\section{- Tato}

O toque é um dos principais determinantes da sensação de bem-estar. A suavidade de um guardanapo, o peso ou a forma dos talheres ou mesmo o conforto de uma cadeira pode afetar a percepção que os clientes têm da empresa ou do local (BARRIOS, 2012). Afeta também o estado como os consumidores reagem com relação aos produtos, provocando atração ou repulsa, como por exemplo, os produtos nas prateleiras dos supermercados podem ser julgados como nojentos ou atraentes, quando pesquisas demonstraram que colocar tampões femininos próximos a batata frita, diminui o apelo da batata. Ainda, os consumidores são menos propensos a comprar determinados produtos se outro comprador o tocou antes (KRISHNA, 2012).

\section{b) Dimensão do sentir}

Consiste em empregar estímulos emocionais para sensibilizar o humor e a emoção do consumidor, que podem variar de um humor positivo até fortes emoções de alegria e orgulho. Geralmente as impressões mais vívidas ocorrem durante o consumo, porém também do contato com o produto no decorrer do tempo. Quanto maior o número de experiências positivas repetidas com o produto ou serviço, mais incisiva e positiva a emoção que será desenvolvida (SCHMITT, 2002). Os sentimentos e as emoções pessoais do consumidor geram determinadas experiências afetivas e emocionais - medo, otimismo, descontentamento, vergonha, amor, alegria, preocupação, inveja, tranquilidade, entusiasmo, tristeza, satisfação, solidão - e é importante que o fornecedor da experiência possa saber a aceitação ou empatia dos consumidores com relação aos estímulos criados (SCHMITT, 2002). A interação pessoal nas situações de consumo é o que provoca mais sentimentos, por causa do contato humano. E esses sentimentos ou emoções podem ser positivos ou negativos.

\section{c) Dimensão cognitiva}

O objetivo aqui é incentivar o pensamento do consumidor, envolvendo-o em um raciocínio elaborado e criativo, que possa inclusive resultar em mudanças de paradigmas, fazendo com que as pessoas possam pensar de outra forma sobre as expectativas existentes (SCHMITT, 2002).

d) Dimensão da ação

“A intenção é criar experiências relacionadas ao corpo, que modifiquem padrões de comportamento, estilos de vida ou interação com outras pessoas" (SCHMITT, 2002, p. 163). Nosso corpo é rico em experiências e é uma fonte fértil de sensações e percepções. Por exemplo, um serviço de manicure ou massagem cria estímulos que estão relacionados a experienciarmos sensações no nosso corpo. A experiência afeta não só o corpo físico, mas através do corpo podemos atingir alguns estados mentais. Determinadas ações motoras ou movimentos corporais podem alterar o estado da nossa mente. Um indivíduo que pratica Tai Chi faz movimentos que resultam em estados mentais mais tranquilos. Também através do corpo podemos executar algumas ações motoras que denotam um comportamento não verbal nas interações sociais, que podem influenciar as atitudes das pessoas. Por exemplo, gestos que podem sugerir aproximação, afastamento ou preferência. Um vendedor pode estar em pé com um gestual que denota descaso, desinteresse e que pode desestimular a aproximação de um cliente, enquanto outro pode mostrar-se solícito através de um sorriso ou uma expressão facial que demonstra simpatia (SCHMITT, 2002).

\section{e) Dimensão relacional}

Esta dimensão aborda as experiências concernentes à interação entre as pessoas, relacionando-a com o contexto social. $\mathrm{O}$ intuito é alcançar uma ligação, uma conexão com outras pessoas ou outros grupos sociais. As situações de compra que não são virtuais são propícias a isto, e quanto mais as pessoas se identificam uma com as outras, maior o significado daquela relação. A identificação pode acontecer também com um grupo social, o que leva a um sentido de pertencimento a um grupo, fazendo também distinção entre outros grupos. 


\section{Aspectos estruturais e funcionais da experiência de consumo}

Caru e Cova (2013) propõem uma análise da experiencia de consumo com base em diferentes intensidades entre dois eixos. Segundo os autores, o primeiro é definido como uma oposição entre acontecimentos ordinários e extraordinários para o consumidor. O segundo indica uma polarização entre as forças exercidas pelo consumidor em contraposição às emanadas da sociedade.

Valendo-se de uma perspectiva bidimensional, Lanier Junior e Rader (2015) discutem uma estrutura de análise das experiências de consumo que detalha explicitamente a relação entre os aspectos estruturais e funcionais.

Com base nas duas dimensões mais amplas (estrutura e função) e suas respectivas subdimensões, Lanier Junior e Rader (2015) propõem uma matriz " $2 \times 2$ " que classifica quatro tipos principais de experiências de consumo: (a) experiências de desempenho (estrutura / função), (b) experiências liberatórias (anti-estrutura / função), (c) experiências estocásticas (estrutura / antifunção) e (d) experiências de aventura (anti-estrutura / antifunção) (LANIER JUNIOR e RADER, 2015, p. 8).

a) Experiências de desempenho

São frequentemente interpretadas como experiências comuns, na medida em que o que distingue essas experiências é a aceitação das estruturas da sociedade, que são frequentemente associadas ao comercial, mundano e profano. De fato, experiências de performance podem ser consideradas como uma celebração dos fatores estruturais da nossa sociedade.

b) Experiências libertadoras

As experiências liberadoras são conceituadas como experiências de consumo que abordam diretamente as relações anti-estruturais (ou seja, instáveis, inconsistentes e desordenadas) que fundamentam uma forma cultural e que produzem e promovem consequências funcionais (ou seja, aparentes, explicáveis e intencionais).

c) Experiências estocásticas

Experiências estocásticas são conceituadas como experiências de consumo que abordam diretamente as relações estruturais (isto é, estáveis, consistentes e dominantes) que fundamentam uma forma cultural, mas que manifestam consequências antifuncionais (ou seja, ambíguas, inexplicáveis e não intencionais) que realmente reforçam e apoiam essas relações estruturais.

d) Experiências de aventura

Nesta tipologia, a aventura não é simplesmente um aspecto de uma experiência, mas é um tipo específico de experiência que se distingue por sua capacidade de resistir a qualquer tentativa de incluí-la em uma forma estrutural ou consequência funcional. Por exemplo, Simmel (1997) argumenta que a aventura tem quatro características distintas: (i) é separada da vida cotidiana, (ii) ativa os aspectos indefinidos, incertos e indeterminados da existência, (iii) transforma a pessoa em um histórico e (iv) é um processo e não um conteúdo.

Entretanto, para melhor entendimento desses conceitos, fez-se necessário a exemplificação e embasamento com pesquisas. O quadro 3 aponta e esclarece esses aspectos:

\section{Quadro 3}

\section{Classificação de experiências de consumo}

\begin{tabular}{|c|c|c|l|}
\hline $\begin{array}{c}\text { Tipos de } \\
\text { Experiências }\end{array}$ & $\begin{array}{c}\text { Relações } \\
\text { Estruturais }\end{array}$ & $\begin{array}{c}\text { Consequencias } \\
\text { Funcionais }\end{array}$ & \multicolumn{1}{c|}{$\begin{array}{c}\text { Domínios } \\
\text { de Pesquisa }\end{array}$} \\
\hline $\begin{array}{c}\text { Experiências de } \\
\text { desempenho }\end{array}$ & Estrutura & Funcional & $\begin{array}{l}\text { Lojas de marca (SHERRY JUNIOR, 1998), ambientes de } \\
\text { varejo (MACLARAN e BROWN, 2005), eventos esportivos } \\
\text { (HOLT, 1995), programas de televisão (FITCHETT, 2004), } \\
\text { videogames (DENEGRI-KNOTT e MOLESWORTH, 2010) e } \\
\text { feiras (PEÑALOZA, 2001). }\end{array}$ \\
\hline $\begin{array}{c}\text { Experiências } \\
\text { libertadoras }\end{array}$ & Anti-estrutura & Funcional & $\begin{array}{l}\text { Magia, fantasia, brincadeiras e criatividade (ARNOULD e } \\
\text { PRICE, 1993; BELK e COSTA, 1998; KOZINETS, 2001). }\end{array}$ \\
\hline $\begin{array}{c}\text { Experiências } \\
\text { Estocásticas }\end{array}$ & Estrutura & Anti-funcional & $\begin{array}{l}\text { Jogos de azar/sorte (COSGRAVE, 2006; } \\
\text { COTTE e LATOUR, 2009; HUMPHREYS, 2010), }\end{array}$ \\
\hline $\begin{array}{c}\text { Experiências de } \\
\text { aventura }\end{array}$ & Anti-estrutura & Anti-funcional & $\begin{array}{l}\text { Turismo, viagens e lazer (EWERT, 1989; PRIEST, 1992; } \\
\text { WEBER, 2001). }\end{array}$ \\
\hline
\end{tabular}

Fonte: Adaptado de Lanier Junior e Rader (2015). 


\section{Discussão dos dados}

Embora as dimensões propostas por Schmitt $(1999,2002,2006,2010)$ sejam amplamente discutidas, existe um problema conceitual ao reunir as cinco dimensões. A dimensão sensorial é equiparada com as demais, pois os estímulos gerados por essa dimensão, são criados pelo marketing e recebidos e interpretados pelos consumidores. $\mathrm{O}$ autor coloca nos mesmos níveis estímulo e reação, chamando de Dimensão as etapas que trazem uma relação de causalidade.

De acordo com a própria interpretação, o consumidor poderá vivenciar a experiência dando alguns significados (ou respostas) para as experiências. Essas respostas são as outras quatro dimensões propostas por Schmitt (2010). Assim, o autor considera estímulos e respostas aos estímulos como se fossem decorrentes da decisão mercadológica, o que não ocorre uma vez que as respostas decorrentes dos estímulos sensoriais (visão, olfato, tato, paladar, audição) poderão ser uma combinação das demais dimensões apresentadas (emoção, cognição, comportamento ou relação social).

A tipologia proposta por Lanier Junior e Rader (2015) é um avanço pela possibilidade de enquadramentos dos tipos de experiência com base nas dimensões de estrutura e função, que são preponderantes para a decisão do consumidor. Entretanto, ao utilizar a estrutura dicotômica de Turner (1969) para estrutura e anti-estrutura, esta tipologia força o enquadramento dos tipos de estrutura de maneira categórica e estática.

Essa fragilidade é replicada usando dicotomicamente a lógica de Merton (1957), o que pode gerar questionamentos para os domínios utilizados pela pesquisa de experiência. A função refere-se às consequências que são aparentes, explicáveis e geralmente pretendidas, e a anti-função refere-se às consequências ambíguas, inexplicáveis e, muitas vezes, não intencionais.

Essa dicotomia dificulta o enquadramento de experiências que possam ser aparentes, mas não sejam intencionais, por exemplo, uma vez que o processo de racionalidade pode indicar um caminho gradual de análise. Assim, a explicabilidade, a intencionalidade de uma experiência pode variar em nível para cada consumidor da mesma experiência, reforçando a importância de adotar uma compreensão mais ampla do significado da situação do consumidor.

Assim como identificamos nas dimensões de Schmitt (SCHMITT, 1999, 2002, 2006, 2010) a necessidade de separação entre o que é definido pelo mercado e o que é definido pelo consumidor, podemos traçar um paralelo entre as relações estruturais e as consequências funcionais usadas por Lanier Junior e Rader (2015). O detalhamento da funcionalidade, como consequência da decisão de marketing, se analisado gradualmente e não categoricamente (funcional e antifuncional), pode ajudar a entender a tipologia das experiências e permitir um melhor esclarecimento sobre as decisões tomadas pelas empresas e os resultados pretendidos da experiência do consumidor.

Compreender o processo que começa com a experiência de marketing, baseado na tomada de decisão do mercado sobre estímulos sensoriais (SCHMITT, 1999, 2002, 2006, 2010) e estrutura (LANIER JUNIOR e RADER, 2015) e que pode fornecer resultados pelos consumidores, de acordo com a funcionalidade (LANIER JUNIOR e RADER, 2015) e as respostas esperadas, sejam elas de emoção, cognição, comportamentos e interações (SCHMITT, 1999, 2002, 2006, 2010), podem trazer contribuições para vários segmentos de mercado que têm a experiência como principal atributo.

\section{CONSIDERAÇÕES FINAIS}

Ao longo das últimas décadas, o conceito de marketing de experiência tem sido transformado, como resultado das interações sociais. Neste artigo buscou-se estudar os aspectos conceituais do marketing de experiência, explorando as definições segundo os principais autores que se dedicaram ao entendimento do campo, além de apresentar os elementos chave e as cinco dimensões da experiência proposta por Schmitt (1999, 2002, 2006, 2010): dimensão sensorial, do sentimento, cognitivo, da ação e relacional. É um dos temas atuais apontado como prioridade de pesquisa de marketing e considerado importante para o entendimento do campo do comportamento do consumidor.

Com base na apreciação crítica dos conceitos relacionados ao Marketing de Experiência, constata-se a diferença em relação ao marketing de consumo, não sendo uma mera evolução deste. A experiência remete a uma tentativa de exploração de sensos e sentidos empregados na apreensão da realidade pelo indivíduo. Em contexto contemporâneo, a discussão é encorpada pela interpolação de fatores sensoriais, com sobre domínio do audiovisual, em meio à escalada de exploração da imagem e do movimento por partes dos veículos de comunicação. Ainda, a busca de formas mais compreensivas de interação com os 
públicos se faz necessária em cenários com tendência à disruptividade, em economias mais afetas à dimensão cognitiva, e pouco relacionadas à análise de estudos lineares.

Conceituar e estabelecer limites de aplicabilidade ao marketing de experiência é valoroso para se estabelecer limites e aplicações, minimizando falsas expectativas e práticas intuitivas, especialmente para as atividades nos setores de serviço e do comércio, que tendem a gerar hiatos na interlocução entre o que se promete e o que se entrega ao consumidor. Pelo estudo das vias complexas a serem desenvolvidas pelas organizações no relacionamento com os públicos, a experiência é um somatório de fatores sinestésicos que envolvem os públicos, as organizações e o contexto no qual estão inseridas.

O desenvolvimento de estruturas e modelos que levem em consideração as decisões tomadas pelas empresas e que estejam relacionados a aspectos intrínsecos ao consumidor, mas que afetem a maneira como as experiências são percebidas e avaliadas, podem ampliar a relevância do marketing experiencial, com maior envolvimento nas experiências dos clientes. 


\section{REFERÊNCIAS}

AHOLA, E. How is the concept of experience defined in consumer culture theory? Discussing different frames of analyses. Kuluttajatutkimus Nyt, v.1, p. 91-98, jan. 2005.

ARNOULD, E. J.; PRICE, L. L. River Magic: Extraordinary Experience and the Extended Service Encounter, Journal of Consumer Research, v.20, n.1, p. 24-45, jun.1993.

ARONNE, C.; VASCONCELOS, M. C. The Impact of Experiential Marketing on the Customer's Perception of a Brand's Essence. In: ENCONTRO DA ANPAD, 33., 2009, São Paulo. Anais... São Paulo: ENANPAD, 2009.

AZAMBUJA, C; BICHUETI, R. Marketing de Experiência: Estratégias para Impulsionar o Market Share e Fortalecer a Marca do Energético Energy. Revista de Administração da UFSM, Santa Maria, v. 9, ed. esp., p. 88-106, ago. 2016.

BARRIOS, M. Marketing de la Experiencia: principales conceptos y características. Palermo Business Review, Buenos Aires, n. 7, p. 67-89, dez. 2012

BATEY, M. O significado da marca: como as marcas ganham vida na mente dos consumidores. Rio de Janeiro: Best Business, 2010.

BELK, R. W.; COSTA, J. A. The Mountain Man Myth: A Contemporary Consuming Fantasy, Journal of Consumer Research, v. 25, n. 3, p. 218-40, dez.1998.

CABRERIZO, A.; SANTOS, L. Marketing Experiencial e Consumo: Eventos de marketing como ferramenta prioritária do marketing experiencial. In: CONGRESSO BRASILEIRO DE CIENCIAS DA COMUNICAÇÃO, 16., São Paulo. Anais... São Paulo: Intercom, 2011.

CARÙ, A; COVA, B. Revisiting consumption experience: a more humble but complete view of the concept. Marketing theory, v. 3, n.2, p. 267-286, jun., 2003.

CERQUEIRA, A.; LOPES, E.; SILVA, J. No Backstage do Marketing da Experiência: A Ótica dos Gestores na Aplicação de Estratégias de Branding por Meio de Ações de Patrocínio e Desenvolvimento de Projetos e Eventos. Future Studies Research Journal, v. 11, n. 1, p. 25-47, jan./abr. 2019.

CLARO, J.; DIAS, A. Estratégia da Razão à Emoção: Experience Marketing e a Marca Líder. Journal of Economic Sociology Studies, v. 4, n. 1, p. 312-325, jan./abr. 2014.

COELHO, M.; SANTOS, P. F. de A. A. dos. Marketing de experiência do smartphone: a cocriação de valor por meio dos aplicativos de celular. Revista Brasileira de Pesquisas de Marketing, Opinião e Mídia, São Paulo, v. 13, p.46-66, out. 2013.

COSGRAVE, J.F. (ed). The Sociology of Risk and Gambling. New York: Routledge, 2006.

COTTE, J.; LATOUR, K. A. Blackjack in the Kitchen: Understanding Online versus Casino Gambling. Journal of Consumer Research, v. 35, n. 5, p. 742-558, set. 2009.

DENEGRI-KNOTT, J.; MOLESWORTH, M. Concepts and Practices of Digital Virtual Consumption. Consumption, Markets and Culture, v. 13, n. 2, p. 109-132, jun. 2010.

EWERT, A. Outdoor Adventure Pursuits: Foundations, Models and Theories. Columbus, OH: Publishing Horizons, 1989.
FARIAS, S. Store Atmospherics and Experiential Marketing: a conceptual framework and research propositions for an extraordinary customer experience. In: ENCONTRO DE MARKETING DA ANPAD, 4., Florianópolis, 2010. Anais... Florianopólis: ANPAD, 2010.

FITCHETT, J. A. The Fantasies, Orders, and Roles of Sadistic Consumption: Game Shows and the Service Encounter. Consumption, Markets and Culture, v. 7, n. 4, p. 285-306, dez. 2004.

FRANCO, N. et al. A Importância do Marketing de Experiência no Fluxo Logístico de um Parque Temático. Estudo de Caso: Walt Disney. South American Development Journal Society, v. 5, n. 2., p. 149161, jul. 2017

FLÔR, P.; UMEDA, G. O Marketing Olfativo como Aplicação do Marketing Experimental: Uso de Aromatizantes no Varejo. In: CONGRESSO BRASILEIRO DE CIENCIAS DA COMUNICAÇÃO, 13., São Paulo, 2008. Anais...São Paulo: Intercom, 2008.

FONTENELLE, I. Cultura do Consumo: fundamentos e formas contemporâneas. Rio de Janeiro: Editora FGV, 2017.

HANNAM, K. Tourism and development II: marketing destinations, experiences and Crises. Progress in Development Studies, v. 4, n. 3, p. 256-263, jul. 2004.

HOLBROOK, M.; HIRSCHMAN, E. The Experiential Aspects of Consumption: Consumer Fantasies, Feelings, and Fun. Journal of Consumer Research, v. 9, p. 132-140, 1982.

HOLBROOK, M. The Millennial Consumer in the Texts of Our Times: Experience and Entertainment. Journal of Macromarketing, v. 20, n. 2, p.178-192, dez. 2000.

HOLT, D.B. How Consumers Consume: A Typology of Consumption Practices, Journal of Consumer Research, v. 22, n.1, p. 1-16, jun.1995.

HUMPHREYS, A. Semiotic Structure and the Legitimation of Consumption Practices: The Case of Casino Gambling, Journal of Consumer Research, v. 37, n.3, p. 490-510, mar. 2010.

ILA-LOPEZ, N.; RODRIGUEZ-MOLINA, M. C. Event-brand transfer in an entertainment service: experiential marketing. Industrial Management \& Data Systems, v. 113, n. 5, p. 712-731, 2013.

KOZINETS, R. V. Utopian Enterprise: Articulating the Meanings of Star Trek's Culture of Consumption, Journal of Consumer Research, v. 28 , n. 1, p. 67-88, jun. 2001.

KRISHNA, A. An integrative review of sensory marketing: Engaging the senses to affect perception, judgment and behavior. Journal of Consumer Psychology, v. 22, n. 3, p. 332-351, jul. 2012.

LANIER JUNIOR, C. D.; RADER, C. S. Consumption Experience: an Expanded View, Marketing Theory, v. 15, n.4, p. 487-508, dez. 2015.

LEE, M.; HSIAO, H.; YANG, M. The Study of the Relationship among Experiential Marketing, Service Quality, Customer Satisfaction and Customer Loyalty. International Journal of Organization Innovation, v.3, n.2, p. 352-378, 2010.

LIMA-FILHO, D. et al. Experiência de consumo em restaurantes comerciais. FACEF Pesquisa, Franca, v. 13, n. 1, p. 80-92, 2010. 
LINDSTROM, M. Brand Sense: How to build powerful brands through touch, taste, smell, sight \& sound. London: Kogan Page Limited, 2005.

LOBUONO, R. et al. Relações entre Dimensões da Experiência, Satisfação, Recomendação e Intenção de Retornar: A Percepção de Participantes de Evento Cultural. PODIUM Sport, Leisure and Tourism Review v. 5, n. 2 maio/ago. 2016.

LOBUONO, R.; GOSLING, M.; RODAS VERA, L. Experiência Em Eventos Culturais: Um Estudo Sobre a Virada Cultural De Belo Horizonte 2014. Turydes Revista Turismo y Desarrollo, n. 20, jun. 2016. Disponível em: <http://www.eumed.net/rev/turydes/20/eventos-culturais. html>. Acesso em: 16 jul. 2017.

MACLARAN, P.; BROWN, S. The Center Cannot Hold: Consuming the Utopian Marketplace, Journal of Consumer Research, v. 32, n. 2, p. 311-323, 2005.

MERTON, R. K. Social Theory and Social Structure. Glencoe, IL: The Free Press, 1957.

MORAL MORAL, M.; FERNÁNDEZ ALLES, M. T. Nuevas Tendencias del Marketing: El Marketing Experiencial. ENTELEQUIA Revista Interdisciplinar, n. 14, p. 237-251, maio 2012.

NEVES, F. et al. A influência da relação afetiva e experiencial no processo de criação de lealdade: uma análise do mercado de telefonia móvel no Brasil. Revista Ciências Administrativas, Fortaleza, v. 23, n. 1, p. 156-185, jan./abr. 2017.

OLIVEIRA, R.; BRAGA, N. Os Cinco Sentidos no Marketing: A Importância dos Estímulos Multissensoriais para Despertar a Emoção e Gerar Inclusão Social. In: CONGRESSO DE CIÊNCIAS DA COMUNICAÇÃO NA REGIÃO SUDESTE, 18., 2013, Bauru, SP,. Anais... Bauru: Intercom, 2013. p. $1-15$

PALMEIRA, M. et al. Experiential Marketing in Bookstores an Analyses of Business Strategy and Customer Experience. In: ENCONTRO DA ANPAD, 33., 2009. São Paulo. Anais... São Paulo: ANPAD, 2009.

PEÑALOZA, L. Consuming the American West: Animating Cultural Meaning at a Stock Show and Rodeo, Journal of Consumer Research, v. 28, n. 3, p. 369-398, dez. 2001.

PETKUS JUNIOR, E. Enhancing the application of experiential marketing in the arts, International Journal of Nonprofit and Voluntary Sector Marketing, v. 9 n. 1, p. 49-56, fev. 2004

PINE II, B. J.; GILMORE, J. H. The Experience Economy: work is theatre and every business a stage. Boston: Editorial Harvard Business School Press, 1998.

PINTO, M.; LARA, J. As Experiências de Consumo na Perspectiva da Teoria da Cultura do Consumo: identificando possíveis interlocuções e propondo uma agenda de pesquisa. Cadernos EBAPE.BR, Rio de Janeiro, v. 9, n. 1, p. 38-56, mar. 2011.

PRIEST, S. Factor Exploration and Confirmation of the Dimensions of an Adventure Experience, Journal of Leisure Research, v. 24, n. 2, p. 127-139, abr. 1992.

ROESLER, G.; MOLIANI, J. O uso da loja conceito e do marketing de experiência no setor de bebidas: um estudo de caso do Bar da Brahma.
In: CONGRESSO BRASILEIRO DE CIÊNCIAS DA COMUNICAÇÃO, 39., 2016. São Paulo. Anais... São Paulo: Intercom, 2016.

SARGI, L; MATTOS, A. O marketing de experiência e a sua importância no cenário mercadológico atual. In: CONGRESSO DE CIÊNCIAS DA COMUNICAÇÃO NA REGIÃO CENTRO-OESTE, 17., 2015, Campo Grande, MS. Anais... Campo Grande: Intercom, 2015. p. 1-10.

SCHMITT, B. Experiential Marketing. Barcelona: Deusto, 2006.

SCHMITT, B. Experiential Marketing. Journal of Marketing Management, v. 15, p. 53-67, fev. 1999.

SCHMITT, B. Experience Marketing: Concepts, Frameworks and Consumer Insights. Foundations and TrendsR in Marketing, v. 5, n. 2, p. 55-112, 2010.

SCHMITT, B. Marketing Experimental. São Paulo: Nobel, 2002.

SCHMITT, B.; ZARANTONELLO, L. Consumer Experience and Experiential Marketing: a critical review. Review of Marketing Research, v. 10, p. 25-61, 2013.

SHAW, C.; IVENS, J. Building Great Customer Experiences. New York: Palgrave MacMillan, 2005.

SHAW, C. The DNA of Customer Experience how emotions drive value. New York: Palgrave MacMillan, 2007.

SHERRY JUNIOR, J. F. The Soul of the Company Store: Nike Town Chicago and the Emplaced Brandscape. In: SHERRY JUNIOR, J. F. (Ed). ServiceScapes: The Concept of Place in Contemporary Markets. Chicago: NTC, 1998. p. 109-146.

SMITH, K; HANOVER, D. Experiential Marketing: Secrets, Strategies, and Success Stories from the World's Greatest Brands. New Jersey: Wiley, 2016

STEFANINI, C. J.; ALVES, C. A.; MARQUES, R. B. Vamos Almoçar? Um Estudo da Relação Hospitalidade, Qualidade em Serviços e Marketing de Experiência na Satisfação dos Clientes de Restaurantes. Revista Brasileira de Pesquisa e Turismo, v. 12, n. 1, p. 57-79, jan./abr. 2018.

STENHOUSE, A. Experience marketing in action: the Fox Kids Cup. Advertising and Marketing to Children, v. 4, n. 4, p. 11-16, 2003.

TURNER, V. W. The Ritual Process: Structure and Antistructure. Ithaca: Cornell University Press, 1969.

YAMAMOTO, P.; CORDOVA, M.; MAZZEI, L. Descrição de um Caso Envolvendo Marketing de Experiência através de Patrocínio Esportivo no Segmento B2b. PODIUM Sport, Leisure and Tourism Review, v.7, n. 1, p. 64-78, jan/abr. 2018.

YUAN, Y. E.; WU, C. K. Relationships Among Experiential Marketing, Experiential Value, and Customer Satisfaction. Journal of Hospitality \& Tourism Research, v. 32, n. 3, p. 387-410, Aug. 2008. Disponível em: <http://journals.sagepub.com/doi/abs/10.1177/1096348008317392>. Acesso em: 16 jul. 2017.

WEBER, K. Outdoor Adventure Tourism: a Review of Research Approaches. Annals of Tourism Research, v. 28, n. 2, p. 360-377, jan. 2001. 
Maria Teresa Grimaldi Larocca

ORCID: https://orcid.org/0000-0002-0177-1101

Doutoranda em Administração pela Universidade Federal da Bahia (UFBA); Mestre em Administração pela Pontifícia Universidade Católica de São Paulo (PUC-SP); Pós-graduada em marketing pela Escola Superior de Propaganda e Marketing (ESPM-SP); Especialização em Marketing pela Università Commerciale Luigi Bocconi; Professora de cursos de Pós-graduação, ministra aulas em disciplinas do curso de marketing, Salvador - BA, Brasil. E-mail: grimaldilarocca@gmail.com

Rodrigo Ladeira

ORCID: https://orcid.org/0000-0001-8243-7270

Doutor em Administração pela Faculdade de Economia e Administração da Universidade de São Paulo (FEA-USP); Pós Doutor pela Stern - New York University; Professor Associado II na Escola de Administração da Universidade Federal da Bahia (UFBA); Professor Permanente do Núcleo de Pós-graduação da Escola de Administração da Universidade Federal da Bahia (NPGA- EAUFBA); Coordenador do Grupo de Pesquisa em Marketing Contemporâneo, Salvador-BA, Brasil. E-mail: rodladeira@yahoo.com

Áurio Lúcio Leocádio da Silva ORCID: https://orcid.org/0000.0003.3175.3382

Doutor em Administração pela Faculdade de Economia e Administração da Universidade de São Paulo (FEA-USP); Professor Adjunto IV do Departamento de Administração pela Universidade Federal do Ceará (UFC-FEAAC); Professor Permanente do Programa em Administração e Controladoria- PPAC-UFC, Coordenador do Grupo de Pesquisa Estratégia para Sociedade Sustentável (LESS), Fortaleza - Ceará, Brasil. E-mail: aurioleocadio42@gmail.com

Ricardo Coutinho Mello

ORCID: https://orcid.org/0000-0002-3265-6595

Doutor em Difusão do Conhecimento pela Universidade Federal da Bahia (UFBA); Professor Adjunto III na Escola de Administração da Universidade Federal da Bahia (UFBA), Salvador, Bahia - Brasil. E-mail: rcmello@ufba.br 